\title{
Evaluation of integrated modular teaching in Chinese ophthalmology trainee courses
}

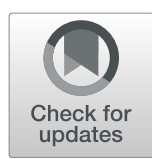

Wei Xin ${ }^{1}$, Yuxian Zou', Yong Ao ${ }^{1}$, Yu Cai ${ }^{1}$, Zheqian Huang ${ }^{1}$, Miaoling Li', Chaochao Xu', Yu Jia', Ying Yang ${ }^{1}$, Yangfan Yang ${ }^{1^{*}}$ and Haotian Lin ${ }^{1,2^{*}}$ (D)

\begin{abstract}
Background: Before attending ophthalmology trainee courses in Zhongshan Ophthalmic Centre, the medical students from Sun Yat-sen University had finished two years of premedical education after the six-year medical courses including basic medical courses, clinical medical courses, clerkship, and research training in medical college. Integrated modular teaching using different problem-based teaching methods in ophthalmology was designed by the teaching steering committee of Zhongshan Ophthalmic Centre. This study aimed to evaluate the effectiveness and satisfaction scales of the integrated modular teaching among the trainee students.

Methods: A total of 100 medical students attending ophthalmology trainee courses in Zhongshan Ophthalmic Centre were enrolled and randomly allocated into 4 groups according to the teaching arrangement. The trainee courses consisted of several sessions delivered in multiple methods, such as "flipped classroom" session and teambased learning session. The pre- and post-class tests were delivered to evaluate the effectiveness of the integrated modular teaching. The satisfaction survey questionnaire was collected from all participants to investigate the degree of satisfaction.
\end{abstract}

Results: Compared with the first-day-test score, the total last-day-test score was significantly improved by a paired $t$-test $(t=3.288, P=0.001)$. Nineteen students obtained a significant improvement in ranking increased by more than 10 in the last-day-test, whereas they failed to obtain a higher average score for daily performance than other students $(t=0.469, P=0.654)$. According to the participant satisfaction questionnaires, these innovative teaching methods were considered as effective and satisfactory.

Conclusions: Integrated modular teaching in ophthalmology trainee courses is effective and appreciated by the medical college students.

Keywords: Ophthalmology, Teaching, Effectiveness, Problem-based, Trainee course

\section{Background}

Ophthalmology is an independent and essential subject in medical teaching in which clinical-skill training and patient interaction play indispensable roles [1]. However, many medical students lack of sufficient practice in ophthalmology due to insufficient teaching time $[2,3]$. In

\footnotetext{
* Correspondence: yangyangfan@gzzoc.com; haot.lin@hotmail.com

'State Key Laboratory of Ophthalmology, Zhongshan Ophthalmic Centre,

Sun Yat-sen University, Guagzhou, 510060 Guangzhou, People's Republic of China

Full list of author information is available at the end of the article
}

addition, the teaching style that most medical colleges employ in teaching ophthalmology may lack efficiency and student interest. With the advancement in science and technology and multimedia innovations over the last several decades, new teaching methodologies have been introduced into medical teaching to improve the learning efficiency, shorten classroom learning time and develop students' ability for autonomous learning. Because ophthalmology is a discipline that emphasizes practice, multimedia teaching method should be adopted to

(c) The Author(s). 2020 Open Access This article is licensed under a Creative Commons Attribution 4.0 International License, which permits use, sharing, adaptation, distribution and reproduction in any medium or format, as long as you give appropriate credit to the original author(s) and the source, provide a link to the Creative Commons licence, and indicate if changes were made. The images or other third party material in this article are included in the article's Creative Commons licence, unless indicated otherwise in a credit line to the material. If material is not included in the article's Creative Commons licence and your intended use is not permitted by statutory regulation or exceeds the permitted use, you will need to obtain permission directly from the copyright holder. To view a copy of this licence, visit http://creativecommons.org/licenses/by/4.0/ The Creative Commons Public Domain Dedication waiver (http://creativecommons.org/publicdomain/zero/1.0/) applies to the data made available in this article, unless otherwise stated in a credit line to the data. 
demonstrate a variety of ocular pictures and videos and to emphasize the items of information repeatedly.

"Flipped classroom" (an inverted model of teaching that uses videos, podcasts or slides to deliver lecture materials outside the classroom, therefore, the classroom time is mainly spent on discussion or problem-solving [4]), team-based learning (TBL) [5], simulation scenarios [6], figure demonstrations [7] and video demonstrations [8] have been shown as effective teaching methodologies to promote the transformation of teaching from a teacher-centred approach to one that focuses on medical students. The use of TBL has been applied in ophthalmology teaching and has proven to be an effective means of active learning [9]. However, most teaching assessments have been implemented based on one or two teaching methodologies [10-13]. Most subjects, including ophthalmology, seldom use a single model for teaching. Instead, a multi-mode teaching model is frequently employed in the actual teaching process. Because every student has a preferred learning mode, it is necessary to integrate a variety of teaching modes to satisfy the students' needs and improve their learning efficiency. Recently, integrated modular teaching using different teaching methodologies has yielded improved results in dermatology [7].

In the present study, 100 medical students from Sun Yat-sen University took part in an ophthalmology curriculum, which was designed to incorporate multiple innovative teaching methodologies. This study was designed to assess the effectiveness and the students' degree of satisfaction among different innovative teaching methods, aiming to evaluate the validity and feasibility of integrated modular teaching in ophthalmology by using pre-, post-class tests and daily performance.

\section{Methods}

\section{Participants}

In this prospective study, 100 medical students who were entering their ninth semester in August 2015 and taking classes in Sun Yat-sen University were enrolled. All students were randomly allocated into 4 groups in order to guarantee the teaching quality. The students participated in a 1-week of integrated modular ophthalmology learning course in Zhongshan Ophthalmic Centre. All the procedures in this study were videotaped, with the approval of the institutional review board of Zhongshan Ophthalmic Centre of Sun Yat-sen University (IRB-ZOCSYSU) (Ethic ID: 2016MEKY062). Written informed consents have been obtained from all students.

\section{Integrated modular teaching}

Each module was initiated by a clinical teacher from Zhongshan Ophthalmic Centre with a suitable introduction, followed by a discussion of individual topics. Pre- and post-class tests were conducted at the beginning of the first module and the end of the last module, respectively, to assess the effectiveness of the integrated modular teaching system. Test papers were designed based on the teachers' discussions and approved by the examination administration of Sun Yat-sen University.

The topics of these modules included the anatomy of the eye, ophthalmologic examination, the lids and lacrimal apparatus, conjunctivitis and uveitis, keratitis, glaucoma, cataract and refractive error, the retina and ocular disorders associated with systemic disease, ocular trauma and blindness (Table 1).

A comprehensive evaluation was conducted among all the enrolled students based on the comparison between the first-day and last-day test scores before and after 1week of integrated modular teaching with innovative teaching methods. The details of the questionnaire utilized in the comprehensive evaluation are illustrated in Supplementary materials. The questionnaire consisted of two parts. The first part was a case with chief complains of single eye redness and blurred vision. Three questions about important signs, diagnosis and recommended examinations of this case were listed to be answered. The second part contained a list of important ocular symptoms and signs, such as photophobia, tearing, itch sensation, foreign-body sensation and swelling pain, etc. Five cases were presented in the 2nd part and the students were asked to select one or more related symptoms or signs for each case.

\section{"Flipped classroom" session}

The "flipped classroom" protocol was used for the ocular trauma teaching among the fifth-year medical college students [14]. Before the "flipped classroom", relevant knowledge and questions based on one case of single ocular trauma were delivered by email. The students were asked to overview the knowledge of ocular trauma in groups using textbooks, published articles, e-publications or any other reference besides the email.

At 3 days before the "flipped classroom" session, the students were directed to review the subject of ocular trauma. One test consisting of three cases was completed by students in $20 \mathrm{~min}$ at 1 day before the "flipped classroom" session. These three cases focused on penetrating injuries, contusions of the eyeball and chemical burns. Two or three questions were appended to each case scenario. Before the end of the course, a post-class test was administered immediately to obtain feedback. Simultaneously, a questionnaire was finished by each student to investigate the satisfaction scale.

\section{Team-based learning module}

The TBL module [15] was designed according to the guidance [16], which included Individual Readiness 
Table 1 Modular teaching on topics of ophthalmology and teaching methodologies

\begin{tabular}{|c|c|c|}
\hline Teaching methodology & Module & Description \\
\hline \multirow[t]{5}{*}{ Lecture } & Anatomy of the eye & \multirow{5}{*}{$\begin{array}{l}\text { Systematic introduction to sensitize and familiarize the student with certain } \\
\text { concepts and clinic features through PPT }\end{array}$} \\
\hline & Ophthalmologic examination & \\
\hline & Lids and lacrimal apparatus & \\
\hline & Cataract and refractive error & \\
\hline & $\begin{array}{l}\text { Retina and ocular disorders associated } \\
\text { with systemic disease }\end{array}$ & \\
\hline \multirow[t]{2}{*}{ Video demonstration } & Anatomy of the eye & \multirow[t]{2}{*}{ Video demonstration of all the steps of a procedure } \\
\hline & $\begin{array}{l}\text { Retina and ocular disorders associated } \\
\text { with systemic disease }\end{array}$ & \\
\hline \multirow[t]{2}{*}{ Practice } & Anatomy of the eye & \multirow[t]{2}{*}{ Basic ophthalmic examination practice and dissecting a pig eyeball } \\
\hline & $\begin{array}{l}\text { Ophthalmologic examination, Cataract } \\
\text { and refractive error }\end{array}$ & \\
\hline \multirow[t]{2}{*}{ Photo demonstration } & Lids and lacrimal apparatus & \multirow{2}{*}{$\begin{array}{l}\text { A series of images of various manifestations of the disease were demonstrated } \\
\text { by projection. The students had to describe what they saw and attempt to } \\
\text { explain the correlation with the clinical condition }\end{array}$} \\
\hline & $\begin{array}{l}\text { Retina and ocular disorders associated } \\
\text { with systemic disease }\end{array}$ & \\
\hline Case-based learning (CBL) & Conjunctivitis and uveitis, Keratitis & $\begin{array}{l}\text { Typical cases from outpatient clinic or hospital ward were demonstrated. The } \\
\text { students had to inquire about medical history, collect clinical examination } \\
\text { information and attempt the diagnosis. A summary of key learning points was } \\
\text { given by the clinical teacher }\end{array}$ \\
\hline Simulation scenario teaching & Glaucoma & $\begin{array}{l}\text { Clinic teachers and students play patients with ocular disease and doctors in a } \\
\text { scenario, o, respectively. Students acted as doctors and asked questions. A } \\
\text { summary of key learning points was given by the clinical teacher. }\end{array}$ \\
\hline Flipped classroom & Ocular trauma & $\begin{array}{l}\text { Some problems were raised from the learning material by the teacher. The } \\
\text { students had to self-study all content, answer all questions and provide new } \\
\text { questions for the discussion in class. }\end{array}$ \\
\hline Team-based learning (TBL) & Blindness & $\begin{array}{l}\text { Students of each group had to complete a presentation associated with the } \\
\text { given topic. }\end{array}$ \\
\hline
\end{tabular}

Assurance Test (IRAT), preparatory assignments, Group Readiness Assurance Test (GRAT), Group Application Problem (GAP) and Final Examination Scores (FESs). In each group, students were given with a random topic in the morning of the first-day trainee course. The topics were closely linked to the content in this curriculum. The students had to prepare any form of presentation within 5 days according to the assigned topic. Other relevant medical knowledge in addition to ophthalmology was permitted to be discussed in the presentation or display. After students in each group presented their team-work presentations in class, the teachers graded the students' presentations into 5 criteria.

\section{Statistical analysis}

The pre- and post-class-test scores, and the first- and last-day-test scores were statistically compared by using paired $t$-test at the significance level of 0.05 . One-way analysis of variance (ANOVA) was used to compare the average scores among different groups or teaching methods. All data analyses were performed using SPSS 20.0 statistical software (SPSS Inc., Chicago, IL, USA).

\section{Results}

\section{Baseline data}

A total of 100 students, 50 male and 50 female, aged from 22 to 28 years old, were recruited. The following information was collected from the student record department of the university: 1) The admission scores for the medical college were collected and no significant difference was observed in the admission scores among four groups $(F=0.520, P=0.669)$, 2) The final grade for all curricula, which are provided as a standard numerical grade (SNG) on a scale from 0 to 100 , including the following subjects: Obstetrics and Gynecology, Pediatrics, Psychiatry, Neurology, Emergency Medicine, Disaster Medicine, Otolaryngology Head and Neck Surgery, Anesthetics, Dermatovenerology, Internal Medicine, Surgery, and Ophthalmology, and there was no significant difference in the final grade for all curricula among four groups, 3) The final grade of ophthalmology theory did not significantly differ among four groups.

\section{Completion rate}

All the 100 clinical medical students who took part in the ophthalmology trainee courses completed pre- and 
post-class tests in the integrated modular teaching provided by Zhongshan Ophthalmic Centre. All data were collected and analysed. Eight clinical teachers jointly completed the innovative teaching work. No complaints from the students were reported throughout the trainee process.

\section{Effectiveness of TBL and "flipped classroom" sessions}

The average scores of pre- and post-class tests in both TBL and "flipped classroom" sessions were calculated and analyzed. The pre- and post-class test scores in each group were statistically compared by using a paired $t$ test. The total students' scores in each group were improved in the post-class test during both TBL and "flipped classroom" sessions (TBL: $t=12.208, P=0.000$; "flipped classroom": $t=37.822 ; P=0.000$ ) (Fig. 1). The students' questionnaires were collected and their acceptance of these two new teaching methods was evaluated by calculating the number of students who responded with "agree" (Table 2). Among them, 70\% of the students believed that these two teaching methods were beneficial for learning. The details and survey questions of student perceptions regarding various teaching methods are presented in Table 2.

\section{Comprehensive evaluation of the integrated modular teaching}

A comprehensive evaluation was conducted among all enrolled students by the first-day-test and last-day-test, which were organized before and after the integrated modular teaching with innovative teaching methods for 1 week. The average scores of each group, including the first-day-test and last-day-test, are presented in Fig. 2. The first-day-test scores did not significantly differ among four groups by ANOVA test. The paired $t$-test was used to compare the average score of first-day-test before the trainee courses and the total last-day-test score after the courses. The total last-day-test score was significantly improved $(t=3.288, P=0.001)$. By comparing the first-day-test and last-day-test scores, 19 students who had outstanding performance with ranking increased by more than 10 in the post-class test were screened. There students were then assigned into the improvement group in Fig. 2, and the daily performance of these outstanding students was assessed to discuss whether they paid more attention in the classroom. However, they did not have higher average scores in daily performance than other students $(t=0.469, P=$ 0.654). Most students were satisfied with the innovative teaching methods based on their answers to the questionnaire. A small number of students did not agree with the effectiveness of these new teaching methods, even if their test results were improved.

\section{Discussion}

With the introduction and development of multimedia, computers and the internet in this information era, modern technologies can increasingly be used to replace the previous teaching methods and to usher in an era of rich teaching resources. The applications of modern technology and abundant public learning resources have promoted a reform from previous teacher-centred to student-centred teaching modes. Student-centred teaching can cultivate higher-order thinking, problem solving and critical analysis, and provide feedback on the learning process [17]. Learning is a complex process, and previous studies have confirmed that increasing active learning can produce a better learning result $[18,19]$. Recently, a variety of student-centred teaching methods have been conducted in medical teaching $[10,20]$.

The trainee courses of ophthalmology are established to improve students' knowledge in clinical practice, to guide them to integrate knowledge in theory with practice, and eventually to attract more outstanding students to the ophthalmology profession. All the teaching modules we are conducting are based on problem-solving.

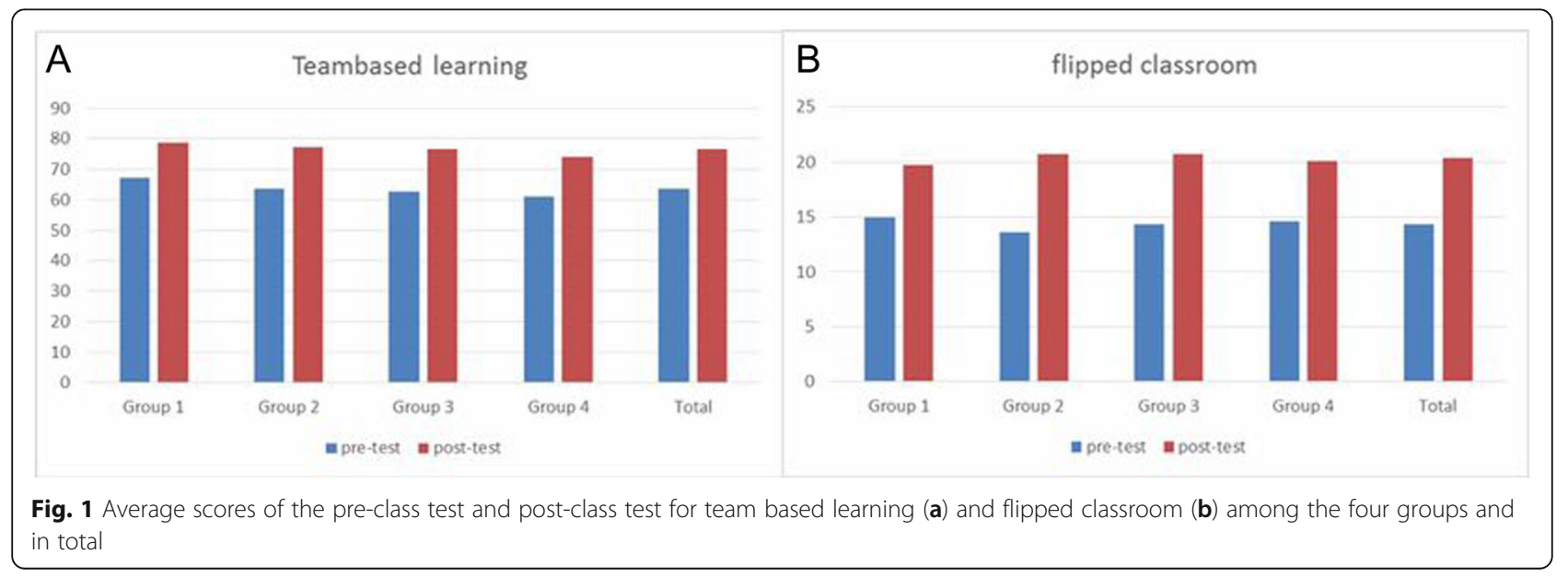


Table 2 Survey of Student Perceptions Regarding Two Teaching Methods

\begin{tabular}{|c|c|c|}
\hline \multirow[b]{2}{*}{ Survey Question } & \multicolumn{2}{|c|}{$\begin{array}{l}\text { Number of Strongly Agree/ } \\
\text { Agree Responses (\%) }\end{array}$} \\
\hline & $\begin{array}{l}\text { Flipped } \\
\text { classroom }\end{array}$ & $\begin{array}{l}\text { Team-based } \\
\text { learning }\end{array}$ \\
\hline $\begin{array}{l}\text { It helped me to reach a higher level } \\
\text { of knowledge }\end{array}$ & 93.30 & 89.41 \\
\hline $\begin{array}{l}\text { It was an effective, motivating learning } \\
\text { process }\end{array}$ & 89.90 & 83.53 \\
\hline It was well organized & 100.00 & 94.12 \\
\hline It challenged me to give my best & 95.00 & 81.18 \\
\hline $\begin{array}{l}\text { It had a positive impact on my } \\
\text { learning attitudes }\end{array}$ & 93.20 & 78.82 \\
\hline $\begin{array}{l}\text { I was satisfied with this teaching } \\
\text { method }\end{array}$ & 89.80 & 75.29 \\
\hline It should be offered more frequently & 81.40 & 75.29 \\
\hline
\end{tabular}

In this study, the effectiveness of each major innovative teaching method was evaluated by pre- and postclass tests for 100 medical students. The post-class scores of all students were improved. A majority of students were satisfied with the innovative teaching methods based on their answers to the questionnaire. Because each student has preferred learning habits and thinking modes, it is understandable that a small number of students do not agree with the effectiveness of these new teaching methods, even if their test results are improved. Overall, integrated teaching modes are appropriate for the learning habits of most students.

A comprehensive evaluation of integrated teaching modes was conducted by comparing the pre- and postclass test scores. Most students presented with significant improvement in the post-class test scores, suggesting that this multi-mode teaching method is highly effective in ophthalmology trainee courses. In previous teaching styles, the teacher-centred teaching method forces students to passively accept knowledge. The grades of students depend on how they listen in the classroom and review the materials after class. Diligent students can often obtain better grades. Therefore, different learning attitudes among students may make an enormous difference in the degree of knowledge they master. However, these innovative teaching methods are implemented based on student-centred teaching, which stimulates autonomous and active learning of the students. These curricula were designed to comprise different modules using a variety of teaching methods, which can enhance learning interests, reduce boredom and increase the acceptance by students.

The multi-mode teaching methods in this study included a "flipped classroom" session, consisted of simulation scenario teaching, case-based learning, and other methods that improved the autonomous learning capability of the students, which plays a pivotal role in the life-long career growth of medical students [21]. Therefore, the education of medical students is not only involved with teaching professional knowledge but also how to take the initiative to study and how to use the educational platforms provided by modern science and technology. In addition, the teamwork capability is of significance for medical students because hospitals are workplaces based on teamwork [22]. The TBL method can teach students how to learn from each other and jointly progress in a team.

Compared with other medical subjects, ophthalmology is more closely associated with advanced science and technologies, such as the application of lasers, new materials, and optical instruments, which require ophthalmologists to maintain effective learning and to develop more autonomous learning than other specialists. Therefore, this teaching method might provide particular assistance

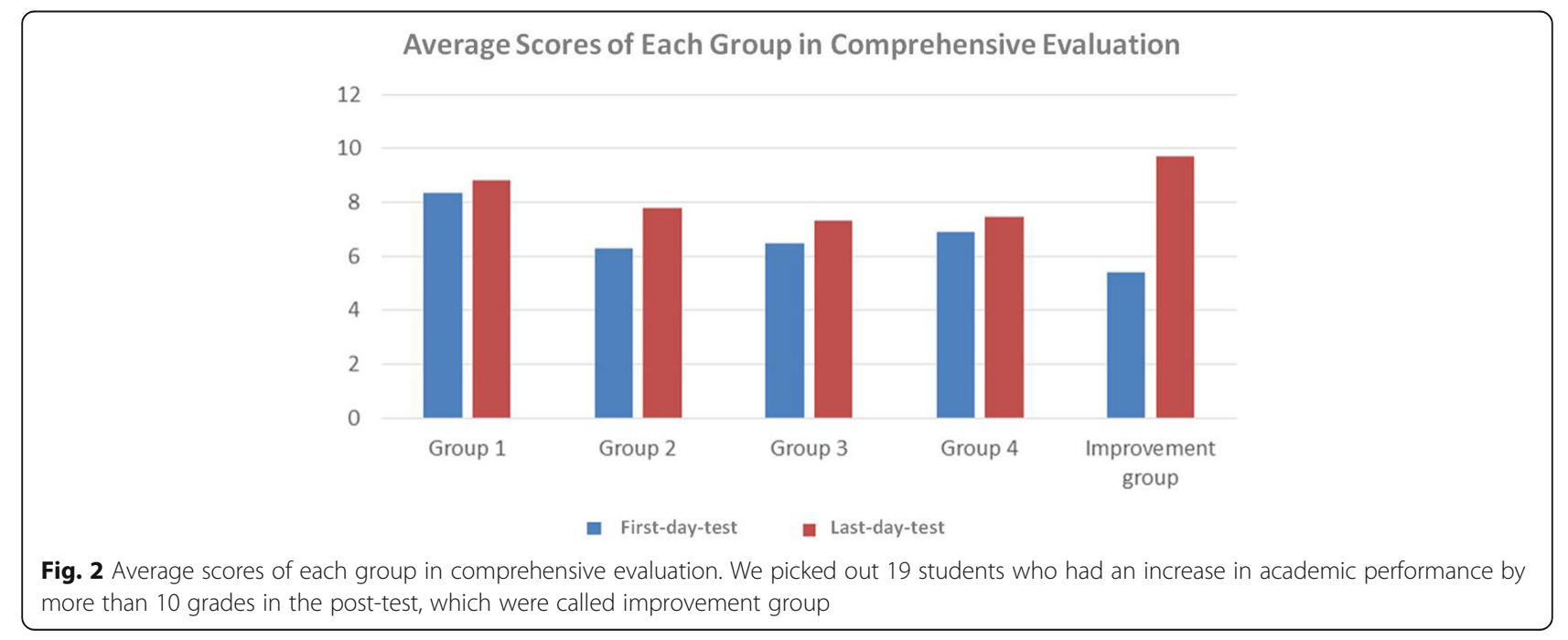


for medical students who are determined to become ophthalmologists.

In our study, the students' daily performance was analysed. All students had worse daily performances in TBL session than the "flipped classroom" and case-based learning sessions, which was consistent with the questionnaire results. TBL had a lower degree of recognition. A total of 19 students obtained an increase in academic performance by more than 10 points in the post-class test, whereas their daily performance in class or attendance were not better compared with other students, probably prompting that all students have excellent class performance when autonomous learning awareness is triggered. This situation differs from previous learning modes because greater efforts have been made throughout the whole learning process, and more significant improvement has been obtained. Nevertheless, whether the learning effect will decrease over time remains elusive. Hence, these students should be followed up to examine their learning ability and the durability of this method in subsequent investigations.

\section{Conclusion}

In the present study, the integrated modular teaching is an effective teaching method and appreciated by medical college students in ophthalmology trainee courses. It deserves to be introduced to the trainee or teaching process in other medical specialized subjects.

\section{Abbreviations}

TBL: Team-based learning; CBL: Case-based learning; ANOVA: One-way analysis of variance

\section{Acknowledgements}

Not Applicable.

\section{Authors' contributions}

WX performed the collection of the data, and was a major contributor in writing the manuscript. $Y Z$ and $Y A$ were in charge of the teaching inspectorate and collected the data. $Y C, Z H$ and $M L$ analyzed and interpreted the data. CX, YJ and YY collected the data. YFY and $\mathrm{HL}$ designed the study protocol and collected the data. All authors read and approved the final manuscript.

\section{Funding}

This study was supported by the National Key R\&D Program of China (2018YFC0116500), National Natural Science Foundation of China (No. 81770967, 81822010), the Science and Technology Planning Project of Guangdong Province (No.2017B030314025, 2018B010109008, 2019B030316012, 2019A070701006), And Guangdong Science and Technology Innovation Leading Talents (No. 2017TX04R031). The sponsors of the study played no role in the study protocol design, data collection, data analysis, data interpretation, manuscript preparation, or the decision to submit the manuscript for publication.

\section{Availability of data and materials}

The datasets used and/or analysed during the current study are available from the corresponding author on reasonable request.
Ethics approval and consent to participate

All the procedures in this study were approved by the Institutional Review Board of Zhongshan Ophthalmic Center of Sun Yat-sen University (Ethic ID: 2016MEKY062). All subjects gave their written informed consent.

\section{Consent for publication}

Not Applicable.

\section{Competing interests}

The authors declare that they have no competing interests.

\section{Author details}

${ }^{1}$ State Key Laboratory of Ophthalmology, Zhongshan Ophthalmic Centre, Sun Yat-sen University, Guagzhou, 510060 Guangzhou, People's Republic of China. ${ }^{2}$ Teaching Reform Research Group, 7\#, Jinsui Road, Guangzhou 510000, China.

Received: 31 July 2019 Accepted: 12 May 2020

Published online: 19 May 2020

\section{References}

1. Walsh K. E-learning in ophthalmology: where next? Indian J Ophthalmol. 2014;62(12):1178.

2. Shah $M$, et al. The state of ophthalmology medical student education in the United States and Canada, 2012 through 2013. Ophthalmology. 2014;121(6): 1160-3.

3. Tsinopoulos IT, et al. Contribution of integrated teaching in the improvement of an undergraduate ophthalmology curriculum. Adv Med Educ Pract. 2014;5:433-7.

4. Strayer JF. How learning in an inverted classroom influences cooperation, innovation and task orientation. Learn Environ Res. 2012:15:171-93.

5. Burgess AW, et al. Applying established guidelines to team-based learning programs in medical schools: a systematic review. Acad Med. 2014;89(4): 678-88

6. Ahn H, Kim HY. Implementation and outcome evaluation of high-fidelity simulation scenarios to integrate cognitive and psychomotor skills for Korean nursing students. Nurse Educ Today. 2015;35(5):706-11.

7. Karthikeyan K, Kumar A. Integrated modular teaching in dermatology for undergraduate students: a novel approach. Indian Dermatol Online J. 2014; 5(3):266-70.

8. Kurien $\mathrm{G}$, et al. Can a multisensory teaching approach impart the necessary knowledge, skills, and confidence in final year medical students to manage epistaxis? J Otolaryngol Head Neck Surg. 2013;42:51.

9. Altintas $L$, et al. Modified use of team-based learning in an ophthalmology course for fifth-year medical students. Adv Physiol Educ. 2014;38(1):46-8.

10. Shetty $S R$, et al. Case-based, team-based learning: a novel method for teaching orofacial syndromology to dental undergraduate students. Educ Health (Abingdon). 2015;28(1):112-3.

11. Wong TH, et al. Pharmacy students' performance and perceptions in a flipped teaching pilot on cardiac arrhythmias. Am J Pharm Educ. 2014; 78(10):185.

12. Aljarallah B, Hassan MS. Problem based learning (PBL) vs. Case based curriculum in clinical clerkship, internal medicine innovated curriculum, student prospective. Int J Health Sci (Qassim). 2015;9(2):147-52.

13. McMullen I, et al. Team-based learning for psychiatry residents: a mixed methods study. BMC Med Educ. 2013;13:124.

14. Yang $Y, X u C-C$, Jia $Y$, et al. Flipped classroom approach to ophthalmology clerkship courses for Chinese students of eight-year program. Ann Eye Sci. 2017;2(7):40.

15. Huang Z, et al. Modified team-based learning in an ophthalmology clerkship in China. PLoS One. 2016:11(4):e0154250.

16. Parmelee DX, Michaelsen LK. Twelve tips for doing effective team-based learning (TBL). Med Teach. 2010;32(2):118-22.

17. Gleason $\mathrm{BL}$, et al. An active-learning strategies primer for achieving abilitybased educational outcomes. Am J Pharm Educ. 2011;75(9):186.

18. Harakuni SU, et al. Effectiveness of team-based learning in microbiology: a non-randomized control study. Educ Health (Abingdon). 2015;28(1):41-4.

19. Jensen $J \mathrm{~L}$, et al. Improvements from a flipped classroom may simply be the fruits of active learning. CBE-Life Sci Educ. 2015;14(1):ar5. 
20. Steedman M, et al. Multimedia learning tools for teaching undergraduate ophthalmology: results of a randomized clinical study. Can J Ophthalmol. 2012;47(1):66-71

21. Dornan T. Workplace learning. Perspect Med Educ. 2012;1(1):15-23.

22. Watts B, et al. Development and implementation of team-based panel management tools: filling the gap between patient and population information systems. Popul Health Manage. 2016;19(4):232-9.

\section{Publisher's Note}

Springer Nature remains neutral with regard to jurisdictional claims in published maps and institutional affiliations.

Ready to submit your research? Choose BMC and benefit from:

- fast, convenient online submission

- thorough peer review by experienced researchers in your field

- rapid publication on acceptance

- support for research data, including large and complex data types

- gold Open Access which fosters wider collaboration and increased citations

- maximum visibility for your research: over $100 \mathrm{M}$ website views per year

At BMC, research is always in progress.

Learn more biomedcentral.com/submissions 